\title{
Disposition of firocoxib in equine plasma after an oral loading dose and a multiple dose regimen
}

\author{
S. Cox ${ }^{\mathrm{a}, *}$, N. Villarino ${ }^{\mathrm{a}}$, C. Sommardahl ${ }^{\mathrm{b}}$, V. Kvaternick ${ }^{\mathrm{c}}$, C. Zarabadipour $^{\mathrm{c}}$, L. Siger $^{\mathrm{d}}$, J. Yarbrough ${ }^{\mathrm{a}}$, \\ A. Amicucci ${ }^{\text {a }}$, K. Reed ${ }^{\mathrm{a}}$, D. Breeding ${ }^{\mathrm{b}}$, T. Doherty $^{\mathrm{b}}$ \\ ${ }^{a}$ University of Tennessee, Department of Biomedical and Diagnostic Sciences, College of Veterinary Medicine, 2407 River Drive, Knoxville, TN 37996, USA \\ ${ }^{\mathrm{b}}$ Large Animal Clinical Sciences, College of Veterinary Medicine, 2407 River Drive, Knoxville, TN 37996, USA \\ ${ }^{\mathrm{c}}$ Merial Limited, PKDM 631, Route 1, North Brunswick, NJ 08902, USA \\ ${ }^{\mathrm{d}}$ Merial Limited, Clinical Operations, 115 Transtech Drive, Athens, GA 30601, USA
}

\section{A R T I C L E I N F O}

\section{Article history:}

Accepted 29 July 2013

\section{Keywords:}

Firocoxib

Horse

Multi-dose regimen

Non-steroidal anti-inflammatory drug

Osteoarthritis

Pharmacokinetics

\begin{abstract}
A B S T R A C T
The objective of this study was to determine if a single loading dose (LD), $3 \times$ the label dose of firocoxib oral paste, followed by nine maintenance doses at the current label dose achieves and maintains near steady state concentrations. Six healthy, adult mares were administered $0.3 \mathrm{mg} / \mathrm{kg}$ of firocoxib on Day 0 , and $0.1 \mathrm{mg} / \mathrm{kg} 24 \mathrm{~h}$ later on Day 1, and at $24 \mathrm{~h}$ intervals from Day 2 to Day 9, for a total of 10 doses. Blood samples were collected throughout the study. The mean firocoxib maximum plasma concentration and standard deviation was $199 \pm 97 \mathrm{ng} / \mathrm{mL}, 175 \pm 44 \mathrm{ng} / \mathrm{mL}$ and $183 \pm 50 \mathrm{ng} / \mathrm{mL}$ after the LD, and first and last maintenance doses, respectively.

The minimum mean concentration $\left(C_{\min }\right)$ increased from $100 \pm 23 \mathrm{ng} / \mathrm{mL}$ after the $\mathrm{LD}$ to $132 \pm 38 \mathrm{ng} / \mathrm{mL}$ at Day 7 . Then, the $C_{\min }$ remained constant until Day 9 . The average concentration at steady state $\left(C_{\text {avg }}\right)$ was $150 \pm 45 \mathrm{ng} / \mathrm{mL}$, which compares well to the $C_{\text {avg }}(130 \pm 36 \mathrm{ng} / \mathrm{mL})$ reported after multiple daily doses at $0.1 \mathrm{mg} / \mathrm{kg}$. The administration of the single LD allowed achievement of the average steady state drug concentrations faster than a multi-dose regimen without a loading dose. After the LD, firocoxib at $0.1 \mathrm{mg} / \mathrm{kg}$ every $24 \mathrm{~h}$ was able to maintain a relatively constant average drug concentration which should produce less variability in onset of action and efficacy.
\end{abstract}

(c) 2013 Elsevier Ltd. All rights reserved.

\section{Introduction}

Firocoxib is the first non-steroidal anti-inflammatory drug (NSAID) of the substituted furanone coxib class to be approved to control pain and inflammation associated with osteoarthritis in horses (NADA 141-253). ${ }^{1}$ One of the most important pharmacodynamic features of firocoxib is that it is a fast-acting cyclo-oxygenase (COX) inhibitor. The time to maximum concentration can occur in $3.9 \mathrm{~h}$ after an oral dose (Kvaternick et al., 2007a). In addition, unlike other NSAIDs used in horses, it is highly selective for the type two inducible form of cyclo-oxygenase (COX-1/COX-2 IC50 ratios of 268-643) (McCann et al., 2002; Lees et al., 2004; Kvaternick et al., 2007b) and therefore COX-1 sparing.

After oral administration, firocoxib is rapidly ( $T_{\max } 3.9 \pm 4.4 \mathrm{~h}$ ) (Kvaternick et al., 2007b) and nearly completely absorbed

\footnotetext{
* Corresponding author. Tel.: +1 8659745646.

E-mail address: scox6@utk.edu (S. Cox).

1 See: http://www.fda.gov/downloads/AnimalVeterinary/Products/Approved

AnimalDrugProducts/FOIADrugSummaries/UCM051453.pdf.
}

(systemic availability of 79\%) with low first pass metabolism (Kvaternick et al., 2007b). In contrast to classical NSAIDs, it is widely distributed in tissues having a large volume of distribution $(1.69 \pm 0.53 \mathrm{~L} / \mathrm{kg})$ (Kvaternick et al., 2007b), despite the high degree of binding to proteins in plasma $(>97 \%)$. It penetrates into many tissues including the synovial fluid (approximately 60\% of plasma concentration) (V. Kvaternick, unpublished data).

One of the most remarkable kinetic features of firocoxib is its long terminal half-life $(29.6 \pm 7.5 \mathrm{~h}$ after single PO administration at label dose) (Kvaternick et al., 2007b). The terminal half-life is about 5-30× longer than that reported for other NSAIDs commonly used in horses, such as phenylbutazone, ketoprofen and flunixin meglumine (Lees, 2009). This long half-life is the result of the combination of two pharmacokinetic factors, namely, a large volume of distribution and/or relatively low total body clearance of the drug.

Hepatic biotransformation, which is the primary mechanism of metabolism of firocoxib, produces metabolites that have little or no pharmacological activity. The metabolic pathways are via dealkylation (major metabolic pathway) and hydroxylation (minor 
metabolic pathway) of the drug (Kvaternick et al., 2007b) followed by urinary excretion. Firocoxib is also glucurono-conjugated in the liver. Both the parent drug and metabolites have been detected in the urine. Renal clearance of firocoxib is minimal and a urine-to-plasma ratio of 0.35:1 was determined (Letendre et al., 2008). Maximum concentrations in urine were detected during the first $1-3 \mathrm{~h}$ after the last dose, and thereafter decreased exponentially and in parallel to concentrations in plasma, with a terminal half-life $\left(t_{1 / 2}\right)$ of $35.3 \pm 7.8 \mathrm{~h}$ after the final dose (Letendre et al., 2008).

Firocoxib has been approved in the United States for daily oral administration at $0.1 \mathrm{mg} / \mathrm{kg}$. This regimen is effective for treatment of horses with osteoarthritis, which requires long term therapy with multiple daily drug administrations (Orsini et al., 2012).

Multiple drug administration at least $3.3 \times$ the terminal half-life leads to drug accumulation until a plateau is reached. Under linear pharmacokinetic conditions, at steady-state there is no further increase in the drug concentration from one dosing interval to the next. As a result, the maximal and minimal concentrations and the degree of fluctuation of the drug concentration in the body are considered to be constant (Tozer and Rowland, 2006). In animals that maintain a constant body clearance of the drug treated using a constant dose and interval, the time to reach steady-state conditions depends on the terminal half-life of the drug. The use of firocoxib according to the label indications (once a day) leads to accumulation of the drug over 5-7 days to reach steady-state (Letendre et al., 2008).

Loading doses (LDs) are used when it is desirable (e.g. from a clinical efficacy standpoint) to reach steady state drug concentrations in the body rapidly rather than waiting to achieve this after repeated administrations at regular intervals. Usually a LD is considered for drugs with an elimination half-life of $24 \mathrm{~h}$ or longer when administered once or twice a day. Firocoxib has an elimination half-life $>24 \mathrm{~h}$, thus, this drug represents an ideal candidate for regimens including loading doses (Tozer and Rowland, 2006). The therapeutic value of using a LD is that it may shorten the time somewhat to achieve a therapeutic response (Tozer and Rowland, 2006).

Considering that the steady-state concentration is reached after 5-7 days of drug administration the objective of this study was to determine if a single $\mathrm{LD}, 3 \times$ the label dose of firocoxib oral paste, followed by nine maintenance doses at the current label dose achieves and maintains near steady-state drug concentrations.

\section{Materials and methods}

Animals

Six, mixed-breed adult mares determined to be healthy based on results of physical examination and history were included in this study. Bodyweights ranged from 371 to $560 \mathrm{~kg}$ and ages ranged from 7 to 19 years. The study was approved by the Institutional Animal Care and Use Committee at the University of Tennessee and Merial Limited.

\section{Procedure}

Horses were housed individually in box stalls for 5 days before and during the experiment. Each horse received two flakes of mixed grass hay two to three times daily and water was available ad libitum.

The horse's mouth was rinsed with water prior to firocoxib administration. Each horse was given $0.3 \mathrm{mg} / \mathrm{kg}$ ( $3 \times$ the current label dose - LD) of firocoxib as Equioxx Oral Paste on Day 0, and $0.1 \mathrm{mg} / \mathrm{kg}$ (current label dose) of firocoxib as Equioxx Ora Paste $24 \mathrm{~h}$ later on Day 1 and $0.1 \mathrm{mg} / \mathrm{kg}$ every $24 \mathrm{~h}$ thereafter on Days 2 through 9 for a total of 10 doses. Blood samples were collected at time 0 (prior to treatment) and $0.25,0.5,1,2,4,6$, and $12 \mathrm{~h}$ post-treatment on Day 0 , prior to treatment on Day 1 , and at the same times after treatment on Day 1 as Day 0 . Blood samples were also collected prior to each treatment on Days 2-9 and at $0.25,0.5,1,2,4,6,12,24,48$, $72,96,120,144$, and 168 h post-treatment on Day 9.
Samples were centrifuged and plasma stored at $-80^{\circ} \mathrm{C}$ until shipped on dry ice to the bioanalytical laboratory. Upon receipt the plasma samples were stored at $-20^{\circ} \mathrm{C}$ until analyzed by a high performance liquid chromatography (HPLC)-fluorescence method. Plasma samples are stable for greater than 2 years at this temperature (Kvaternick et al., 2007a).

\section{Firocoxib HPLC analysis}

Firocoxib was separated on a Zorbax $\operatorname{RxC}_{18}(150 \times 4.6 \mathrm{~mm}, 5 \mu \mathrm{m})$ column with a Zorbax $\mathrm{RxC}_{18}$ guard column (Agilent). The mobile phase was a mixture of methanol:water $(51: 49 \mathrm{v} / \mathrm{v})$. The flow rate was $1 \mathrm{~mL} / \mathrm{min}$ and the column temperature was $40^{\circ} \mathrm{C}$. The excitation wavelength was $250 \mathrm{~nm}$ and the emission wavelength was $375 \mathrm{~nm}$.

Plasma sample preparation included the use of a protein precipitation plate. Briefly, previously frozen plasma was thawed, mixed, and centrifuged. Six hundred microliters of acetonitrile were added to the wells of a 96-well protein precipitation plate followed by $0.2 \mathrm{~mL}$ of plasma and allowed to equilibrate for $\sim 3 \mathrm{~min}$. A vacuum was applied and the eluate collected in a $2-\mathrm{mL}$ collection plate. The eluate was evaporated to dryness and reconstituted in $0.2 \mathrm{~mL}$ of $40 \%$ acetonitrile/water and $50 \mu \mathrm{L}$ were injected. With each set a neat standard curve was prepared in the linear concentration range of $2.5-250 \mathrm{ng} / \mathrm{mL}$ along with a minimum of six quality control or fortified samples. The grand average recovery was $102 \%$ and the intra- and interassay variability was $<15 \%$.

Pharmacokinetic analysis

Pharmacokinetic parameters for firocoxib were calculated using WinNonlin 5.0.1 (Pharsight). Values for plasma half-life $\left(t_{1 / 2}\right)$, steady-state average plasma concentrations, area under the plasma concentration time curve from time 0 to infinity, last and tau $\left(\mathrm{AUC}_{0-\infty}, \mathrm{AUC}_{0-\text { last }}, \mathrm{AUC}_{0_{-\mathrm{tau}}}\right)$ and percent fluctuation were calculated from non-compartmental analysis (linear/log trapezoidal model). The maximum and minimum concentrations and times to those observations were observed values.

\section{Results}

Samples were assayed to evaluate the plasma concentration profiles and pharmacokinetic behavior. There were no adverse effects observed in any of the horses through the experiment. The plasma pharmacokinetic parameters after the administration of a LD and nine consecutive daily doses are presented in Table 1. A semilogarithmic plot was generated of the individual animal and mean plasma drug concentration-versus-time curves after the oral LD and oral administration of nine maintenance doses (Figs. 1 and 2).

After the administration of the LD of firocoxib, the concentration in plasma increased to an average maximum concentration of $199 \pm 97 \mathrm{ng} / \mathrm{mL}$ at $9.25 \pm 8.81 \mathrm{~h}$. After the first maintenance dose of $0.1 \mathrm{mg} / \mathrm{kg}$ the average maximum concentration was $175 \pm 44 \mathrm{ng} / \mathrm{mL}$ at $3.46 \pm 4.74 \mathrm{~h}$ post-administration of firocoxib. After the last firocoxib administration, the average maximum concentration was $183 \pm 50 \mathrm{ng} / \mathrm{mL}$ at $5.75 \pm 5.32 \mathrm{~h}$.

The administration of the maintenance dose led to the accumulation of the drug until the steady-state concentration was reached. The mean minimum concentration increased from $100 \pm 23 \mathrm{ng} / \mathrm{mL}$ after the LD to $132 \pm 38 \mathrm{ng} / \mathrm{mL}$ at Day 7 and remained constant until Day 9. The increased concentration of firocoxib in the body was evident for all the horses except for horse 1 . In this animal there was no accumulation of drug during the first four maintenance doses.

The dosing scheme used in our study does lead to steady state drug concentrations with a relatively small degree of fluctuation between the maximum and minimum concentrations. The degree of fluctuation was $<50.4 \%$ for all of the animals except horse 1 (79.6\%) (Table 1).

After 9 days of administration of the drug at label dose plus the LD at three times, plasma concentrations decreased in a monoexponential manner and the average half-life was 1.74 days $(41.7 \mathrm{~h})$. In this study all the animals were clinically healthy through the entire experiment but we did not evaluate biochemical variables. 
Table 1

Individual and average pharmacokinetic parameters of firocoxib in horses after an oral loading dose of $0.3 \mathrm{mg} / \mathrm{kg}$ followed by nine daily doses of $0.1 \mathrm{mg} / \mathrm{kg}$.

\begin{tabular}{|c|c|c|c|c|c|c|c|}
\hline Pharmacokinetic parameter & Horse 1 & Horse 2 & Horse 3 & Horse 4 & Horse 5 & Horse 6 & Mean \pm SD \\
\hline$t_{1 / 2}$ (days) & 0.72 & 1.76 & 2.32 & 1.66 & 1.82 & 2.14 & $1.74 \pm 0.56$ \\
\hline$T_{\max }$ (days) & 9.01 & 9.01 & 9.25 & 9.17 & 9.5 & 9.5 & $9.24 \pm 0.22$ \\
\hline$C_{\max }(\mathrm{ng} / \mathrm{mL})$ & 110 & 170 & 227 & 243 & 200 & 149 & $183 \pm 50$ \\
\hline$C_{\min }(\mathrm{ng} / \mathrm{mL})$ & 49 & 116 & 141 & 154 & 168 & 121 & $125 \pm 42$ \\
\hline$C_{\mathrm{avg}}(\mathrm{ng} / \mathrm{mL})$ & 76 & 130 & 170 & 197 & 189 & 139 & $150 \pm 45$ \\
\hline $\mathrm{AUC}_{\text {tau }}($ days.ng/mL) & 76 & 130 & 170 & 197 & 189 & 139 & $150 \pm 45$ \\
\hline $\mathrm{AUC}_{0-\text { last }}$ (days.ng/mL) & 129 & 359 & 178 & 601 & 589 & 460 & $476 \pm 210$ \\
\hline $\mathrm{AUC}_{0-\infty}$ (days.ng/mL) & 132 & 376 & 838 & 641 & 632 & 506 & $521 \pm 245$ \\
\hline$\%$ AUC extrapolation & 2.42 & 4.57 & 14.3 & 6.29 & 6.91 & 9.18 & $7.28 \pm 4.12$ \\
\hline$\%$ Fluctuation & 79.6 & 41.2 & 50.4 & 45.6 & 16.7 & 20.1 & $42.3 \pm 22.9$ \\
\hline
\end{tabular}

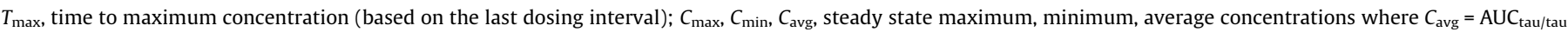

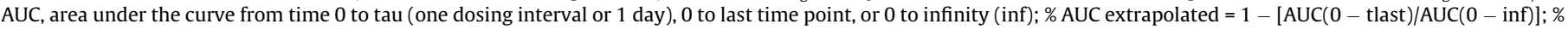
fluctuation $=100 *\left(C_{\max }-C_{\min }\right) / C_{\text {avg. }}$

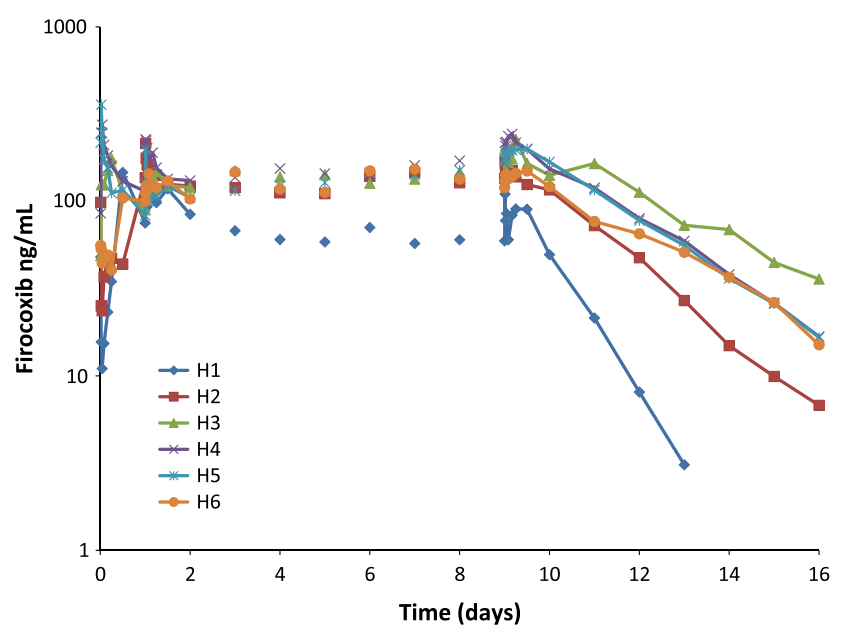

Fig. 1. A semilogarithmic plot was generated of the individual animal drug concentration-versus-time curves after the oral loading dose and oral administration of nine maintenance doses.

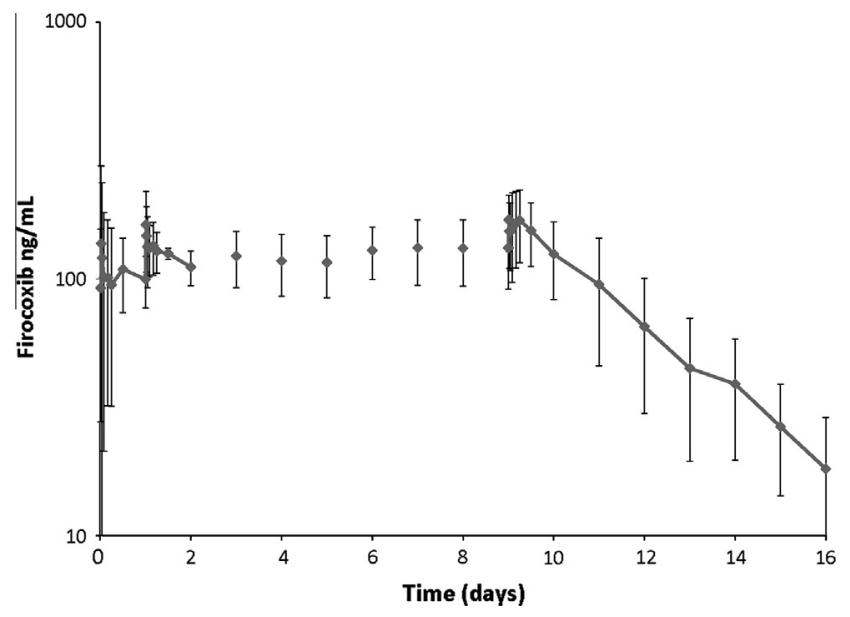

Fig. 2. A semilogarithmic plot was generated of the mean plasma drug concentration-versus-time curves after the oral loading dose and oral administration of nine maintenance doses.

\section{Discussion}

After the LD, the maximum drug concentration in plasma was observed within $24 \mathrm{~h}$ of administration but $T_{\max }(0.5-24 \mathrm{~h})$ and other pharmacokinetic parameters were variable among the animals. This is not unexpected since orally administered drugs characteristically have greater pharmacokinetic variability (Bouckaert et al., 1994; Soma et al., 2001) as a result of multiple factors that may influence the process of absorption, e.g., gastric emptying time, the presence of feed in the horse's mouth, buccal absorption, formulation, etc., and which also vary between animals. As seen in our results, this PK parameter also had a large variability in other experiments with firocoxib (Kvaternick et al., 2007b; Letendre et al., 2008; Cox et al., 2012), and is a common phenomenon especially with horses and herbivores where drugs may bind to hay (Lees et al., 1988).

Firocoxib is highly selective for the type 2 inducible form of cyclo-oxygenase (COX-1/COX-2 IC50 ratios of 268-643) (McCann et al., 2002; Lees et al., 2004; Kvaternick et al., 2007a,b) and therefore COX-1 sparing. Inhibitory concentrations of COX (IC50, IC80, IC95, etc.) are generated in vitro and used as indicators of potency and can be integrated with plasma concentration time profiles generated in vivo (Lees et al., 2004). Equine whole blood assays showed that the concentration of firocoxib required to inhibit $50 \%$ of the COX-2 enzyme (IC50) ranged from 0.0369 to $0.12 \mu \mathrm{M}$, while the IC50 for $\mathrm{COX}=1$ is $20.14-33.1 \mu \mathrm{M}$ (see EMA Product Summary). ${ }^{2}$ The IC50 concentration for COX-1 was not exceeded at any time during our study and in fact plasma concentrations on average fluctuated around the IC90 concentration from Days 0 to 9 and were above the IC50 on day 15 (unpublished data).

The administration of the LD led to an average maximum concentration $(199 \pm 97 \mathrm{ng} / \mathrm{mL})$ comparable with the maximum concentration at steady-state after multiple single dose administrations $(173 \pm 44 \mathrm{ng} / \mathrm{mL}$ ) (Letendre et al., 2008) as shown in Table 2 . This indicates the use of a $3 \times$ LD may lead to tolerable drug concentrations in plasma.

Using data (0-24 h) from 3/6 horses, the mean terminal half-life after the LD was estimated to be $30 \mathrm{~h}$, which is similar to that after a single label dose (Kvaternick et al., 2007b; Cox et al., 2012) and a single $3 \times$ dose (unpublished data). In contrast, the mean terminal half-life of firocoxib after 10 doses (LD + MD) was about $42 \mathrm{~h}$. This change in the mean elimination half-live was observed in an earlier study using a multiple dose (at $0.1 \mathrm{mg} / \mathrm{kg}$ PO or $0.2 \mathrm{mg} / \mathrm{kg} \mathrm{IV}$ ) regimen without a LD (Letendre et al., 2008). The mean terminal halflives were 36.5 or $44.2 \mathrm{~h}$ when firocoxib was given PO or IV at regular intervals for 9 days. In the present study, the change in the disposition of the drug may indicate among other things a change in the absorption rate constant, or a decrease in clearance and/or increase in the volume of distribution of the drug.

\footnotetext{
2 See: http://www.ema.europa.eu/docs/en_GB/document_library/EPAR_-_Product Information/veterinary/000142/WC500065939.pdf (accessed 15 July 2013).
} 
Table 2

Average \pm SD values for maximum firocoxib plasma concentrations $\left(C_{\max }\right)$ following multiple dose regimen of firocoxib with a loading dose and following a multiple single dose regimen of firocoxib $(0.1 \mathrm{mg} / \mathrm{kg})^{\mathrm{a}}$.

\begin{tabular}{lcc}
\hline \multicolumn{1}{c}{ Dosing } & $\begin{array}{c}\text { Loading dose } \\
\text { regimen, } \mathrm{ng} / \\
\mathrm{mL} \pm \mathrm{SD}\end{array}$ & $\begin{array}{c}\text { Multiple single dose } \\
\text { regimen }\end{array}$ \\
\hline $\begin{array}{c}\text { After loading dose } \\
\text { After first (maintenance) } \\
\text { dose }\end{array}$ & $199 \pm 97$ \\
$\begin{array}{c}\text { After last (maintenance) } \\
\text { dose (i.e., steady state) }\end{array}$ & $183 \pm 50$ & $\begin{array}{c}\text { Not applicable } \\
45.0 \pm 11.3\end{array}$ \\
\hline a Letendre et al. (2008). & & $173 \pm 44$ \\
\end{tabular}

These are factors that can affect the half-life of a drug, since the LD in and of itself does not. Firocoxib undergoes hepatic biotransformation so saturation of the hepatic metabolism of firocoxib may occur and consequently alter the processes of drug elimination. These observations are relevant in the context of potential use in sport horses where changes in half-life may have an impact on the time required for drug concentrations to fall below the legal drug concentration limit.

In the present study the average maximum concentration of firocoxib after the first label dose and at steady-state was comparable to those observed at steady state (7 days) after multiple administrations of the drug at the label dose without a LD (Letendre et al., 2008). Thus, the main advantage of including the LD is the achievement of near steady-state concentrations after the first day of treatment rather than 7 days after the initiation of the therapy. This could clearly have an impact on the onset of action and effect of the drug during the first days of administration until steady-state concentrations are reached.

After a $3 \times$ LD followed by 9 days of firocoxib administration at the label dose, the mean maximum concentration $\left(C_{s s, \max }\right)$ in plasma after the last dose was double the plasma concentration obtained after a single label dose without the LD, $183 \mathrm{ng} / \mathrm{mL}$ versus $91 \mathrm{ng} / \mathrm{mL}$, respectively (Cox et al., 2012). This is the result of drug accumulation to steady state due to repeated administration of the drug at regular intervals. This drug accumulation is clearly reflected in the mean $\mathrm{AUC}_{0 \text {-tau }}$. The $\mathrm{AUC}_{0 \text {-tau }}$ was approximately $4 \times$ greater than that reported in the literature after a single administration at label dose without a LD (Cox et al., 2012) and comparable to $\mathrm{AUC}_{0 \text {-tau }}$ reported in literature following multiple doses (Letendre et al., 2008).

One animal had a limited accumulation compared to other animals. Under linear pharmacokinetic conditions, the degree of drug accumulation and fluctuation of drug concentration within a dose interval in the body depends on the ratio between the dose interval and the elimination half-life of the drug. The larger this ratio is the less drug accumulation and the wider fluctuation of the drug concentration in plasma. Thus, one of the potential reasons for the findings in horse 1 is a larger dose interval-elimination half-life ratio due to a much shorter elimination half-life in comparison with the rest of the animals (Table 1 ). A shorter half-life and and/or a hypothetical decrease of drug absorption may lead to a lack of accumulation of the drug.

A shorter half-life may be due to a smaller volume of distribution and/or a larger body clearance. Animals with shorter terminal half-lives may require either larger maintenance doses or a more frequent drug administration in order to accumulate drug in the body and reach drug concentrations comparable with the rest of the animals. Otherwise the average drug concentration at steadystate will be lower and fluctuations will be wider.

\section{Conclusions}

The administration of a multiple dosing regimen with a single LD at three times the label dose followed by nine maintenance doses allowed the achievement of targeted average drug concentrations faster than a multi-dose regimen without a LD. The administration of firocoxib at $0.1 \mathrm{mg} / \mathrm{kg}$ every $24 \mathrm{~h}$ after the LD was able to maintain a relatively constant average drug concentration.

\section{Conflict of interest statement}

Merial Limited provided funding for the study. None of the authors of this paper had a financial or personal relationship with other persons of organizations that could inappropriately influence or bias the content of this paper.

\section{Disclaimer}

This document is provided for scientific purposes only. Any reference to a brand or trademark herein is for informational purposes only and is not intended for a commercial purpose or to dilute the rights of the respective owner(s) of the brand(s) or trademark(s).

\section{Acknowledgements}

We would like to thank Merial Limited for funding this project and their Pharmacokinetic and Metabolism division for sample analysis. Preliminary results were presented as a poster at the ACVIM Forum, New Orleans, LA, 30 May-2 June 2012.

\section{References}

Bouckaert, S., Voorspoels, J., Vandenbossche, G., Deprez, P., Remon, J.P., 1994. Effect of drug formulation and feeding on the pharmacokinetics of orally administered quinidine in the horse. Journal of Veterinary Pharmacology and Therapeutics 17, 275-278.

Cox, S., Dudenbostel, L., Sommardahl, C., Yarbrough, J., Saleh, M., Doherty, T., 2012. Pharmacokinetics of firocoxib and its interaction with enrofloxacin in horses. Journal of Veterinary Pharmacology and Therapeutics 35, 615-617.

Kvaternick, V., Malinski, T., Wortmann, J., Fisher, J., 2007a. Quantitative HPLC-UV method for the determination of firocoxib from horse and dog plasma. Journal of Chromatography B 854, 313-319.

Kvaternick, V., Pollmeier, M., Fischer, J., Hanson, P.D., 2007b. Pharmacokinetics and metabolism of orally administered firocoxib, a novel second generation coxib, in horses. Journal of Veterinary Pharmacology and Therapeutics 30, 208-217.

Lees, P., Taylor, J.B.O., Higgins, A.J., Sedgwick, A.D., 1988. In vitro and in vivo binding of phenylbutazone and related drugs to equine feed and digesta. Research in Veterinary Science 44, 50-56.

Lees, P., Landoni, M.F., Giraudel, J., Toutain, P.L., 2004. Pharmacodynamics and pharmacokinetics of nonsteroidal anti-inflammatory drugs in species of veterinary interest. Journal of Veterinary Pharmacology and Therapeutics 27, 479-490.

Lees, P., 2009. Analgesic, antiinflammatory, antipyretic drugs. In: Veterinary Pharmacology and Therapeutics, Ninth Ed. Willey-Blackwell, Ames, IA, USA, pp. 457-492.

Letendre, L.T., Tessman, R.K., McClure, S.R., Kvaternick, V.J., Fischer, J.B., Hanson, P.D., 2008. Pharmacokinetics of firocoxib after administration of multiple consecutive daily doses to horses. American Journal of Veterinary Research 69, 1399-1405.

McCann, M.E., Anderson, D.R., Brideau, C., Black, W.C., Zhang, D.H., Hickey, G.J., 2002. In vitro efficacy activity and in vivo efficacy of a novel COX-2 inhibitor in the horse. Preliminary findings. In: Proceedings, ACVIM Forum 2002, Dallas, TX, pp. 789 .

Orsini, J.A., Ryan, W.G., Carithers, D.S., Boston, R.C., 2012. Evaluation of oral administration of firocoxib for the management of musculoskeletal pain and lameness associated with osteoarthritis in horses. American Journal of Veterinary Research 73, 664-671.

Soma, L.R., Uboh, C.E., Guan, F., Birks, E.K., Teleis, D.C., Rudy, J.A., Tsang, D.S., Watson, A.O., 2001. Disposition, elimination and bioavailability of phenytoin and its major metabolite in horses. American Journal of Veterinary Research 62, 483-489.

Tozer, Rowland, 2006. Introduction to pharmacokinetics and pharmacodynamics. In: The Quantitative Basis of Drug Therapy. Lippincott Williams and Wilkins, Baltimore, MD, pp. 189-216. 